Check for updates

St George's, University of London, London, UK

2 St George's University Hospitals NHS

Foundation Trust, London, UK

Correspondence to: D Gill

dgill@sgul.ac.uk

Cite this as: BMJ2021;373:n1215

http://dx.doi.org/10.1136/bmj.n1215

Published: 17 May 2021

\section{Antivirals against SARS-CoV-2 by autumn?}

\author{
An over ambitious target that risks forced errors
}

David Smith, 1, 2 Dipender Gill ${ }^{1}, 2$

The UK government has launched a covid-19 antivirals taskforce with the aim of deploying drugs for home treatment by autumn this year. ${ }^{1}$ The description suggests that the government wants direct acting orally administered drugs that reduce replication and help eliminate SARS-CoV-2 from the body. Taken after a positive swab test result or prophylactically after exposure, these drugs could reduce viral transmission, morbidity, and mortality.

And they may well be needed. Vaccine efficacy against symptomatic disease is $67-95 \%$, with unknown durability and effectiveness against new variants. ${ }^{2}$ Peak viral loads seem to determine the duration and severity of symptoms, ${ }^{3}$ but current covid-19 treatments are largely limited to anti-inflammatory drugs (dexamethasone, tocilizumab, and sarilumab) that save only around one in three patients who would otherwise have died. ${ }^{4}$ Remdesivir, the most commonly used antiviral for SARS-CoV-2 in the UK, requires intravenous administration and seems to offer little survival benefit. $^{4}$

\section{The challenge}

Viruses encode few proteins. They instead rely on host enzymes for replication and thus offer few viable drug targets. None of the currently available oral antiviral drugs are licensed for coronaviruses, and investigation into their use against SARS-CoV-2 in clinical trials has not been encouraging. ${ }^{4}$ Despite this, close to a hundred licensed antivirals are available for other pathogens and collectively save millions of lives every year. ${ }^{5}$ Most are highly specific for their target virus, and activity against different viruses is the exception rather than the rule. ${ }^{4}$ The European Union has shortlisted some intravenous medications for development, but these would not fit the UK government's brief of oral drugs to be taken at home. ${ }^{6}$

Of the available oral compounds with broad spectrum antiviral activity, only ribavirin is licensed to treat multiple virus strains, and this is usually in combination with other drugs. ${ }^{5}$ As it has toxic effects, ribavirin is unlikely to be suitable for covid-19 prophylaxis. Favipiravir and nitazoxanide have been shown to inhibit a large number of viruses in vitro, but phase III trials have been completed only for influenza. ${ }^{8}$ Medications against other pathogens might also have anti-SARS-CoV-2 activity, ${ }^{8}$ but several repurposing attempts have ended in disappointment, including ivermectin, azithromycin, and hydroxychloroquine. ${ }^{4}$

Viruses also have very short replication times and generate large numbers of copies, resulting in mutations that can confer resistance against antiviral drugs. ${ }^{5}$ In the 1980 s, trials showed that

azidothymidine improved survival in people with $\mathrm{HIV}$ infection, and the drug was initially viewed as a success before viral resistance emerged.$^{9}$ It became clear that patients required a combination of three drugs in order to avoid resistance..$^{10}$ More recently, the pandemic influenza strain $\mathrm{H}_{1} \mathrm{~N}_{1}$ has developed resistance to oseltamivir. ${ }^{11}$ If SARS-CoV-2 shares this capacity to generate escape mutations, then multiple antiviral drugs may be required in combination for effective treatment or prophylaxis.

\section{The targets}

SARS-CoV-2 does present a few potential targets for antiviral therapy. Strong evidence suggests that viral particles enter human cells using the angiotensin converting enzyme 2 receptor and a cell surface protease, TMPRSS2. ${ }^{8}$ Camostat is a TMPRSS2 inhibitor that seems safe in humans, and phase II trials are currently in progress. ${ }^{12}$ The virus may exploit enzyme components of the vesicle transport system, such as PI-3P-5-kinase (PIKfyve) to enter the host cell membrane. ${ }^{13}$ Early laboratory studies on apilimod, a PIKfyve inhibitor, look encouraging. ${ }^{14}$

Other possible targets include the virally encoded RNA dependent RNA polymerase (RdRp), which replicates the SARS-CoV-2 genome and is dissimilar to host enzymes. It seems to be highly conserved between strains, suggesting lower risk of resistant mutations. ${ }^{15}$ Favipiravir is thought to block $R d R p^{16}$ and is now in phase III trials. The nucleoside analogue molnupiravir, which also targets RdRp, reduces viral transmission and disease severity in ferrets and has been well tolerated in phase I clinical trials. $^{17}$

SARS-CoV-2 also produces 3 CL protease, which is used for building viral particles from polypeptides. Protease inhibitors could therefore prevent virus assembly. ${ }^{8}$ Nitazoxanide may work by inhibiting both cell entry and viral particle assembly ${ }^{18}$ and seemed to improve viral clearance in patients with symptomatic covid-19 in one small trial. ${ }^{8}$ Although the government specifies oral treatments, mucosal topical medications given by nasal spray may be as effective-iota-carrageenan, a complex sugar molecule derived from seaweed, is in phase II trials after encouraging results in vitro. ${ }^{19}$

Efforts to repurpose existing drugs to inhibit SARS-CoV-2 have so far been unsuccessful, and while promising new agents are under clinical development, proper evaluation of efficacy and safety will take time. Effective antivirals would be highly valuable in the fight against covid-19, yet policy must be realistic and based on evidence, not hope or unfounded optimism. The UK government's target to 
deliver antiviral home treatments within the next few months seems overly ambitious, and care must be taken to ensure that the rush does not force blunders, or indeed repeat previous ones. ${ }^{20}$

Competing interests: We have read and understood BMJ policy on declaration of interests and declare the following: DG is employed part time by Novo Nordisk and has received consultancy fees from Policy Wisdom, unrelated to the submitted work.

Provenance and peer review: Commissioned; not externally peer reviewed.

We thank Mark J Ponsford for his comments

1 Mahase E. Covid-19: UK launches antivirals taskforce to deliver home treatments by autumn. BMJ 2021;373:n1077. doi: 10.1136/bmj.n1077 pmid: 33903129

2 Olliaro P, Torreele E, Vaillant M. COVID-19 vaccine efficacy and effectiveness-the elephant (not) in the room. Lancet Microbe 2021. doi: 10.1016/S2666-5247(21)00069-0. pmid: 33899038

3 Weiss A, Jellingsø M, Sommer MOA. Spatial and temporal dynamics of SARS-CoV-2 in COVID-19 patients: A systematic review and meta-analysis. EBioMedicine 2020;58:102916. doi: 10.1016/j.ebiom.2020.102916 pmid: 32711256

4 Welte T, Ambrose LJ, Sibbring GC, Sheikh S, Müllerová H, Sabir I. Current evidence for COVID-19 therapies: a systematic literature review. Eur Respir Rev 2021;30:200384. doi: 10.1183/16000617.0384-2020 pmid: 33731328

5 De Clercq E, Li G. Approved antiviral drugs over the past 50 years. Clin Microbiol Rev 2016;29:695-747. doi: 10.1128/CMR.00102-15 pmid: 27281742

6 Boffey D. EU wants to mass produce three "course-changing” Covid drugs from October. Guardian 2021 May 6. hitps://www.theguardian.com/world/202//may/06/dnug-changecourse-pandemictrialled-for-useeuropean-commission

7 Rossignol JF. Nitazoxanide: a first-in-class broad-spectrum antiviral agent. Antiviral Res 2014;110:94-103. doi: 10.1016/j.antiviral.2014.07.014 pmid: 25108173

8 Tarighi P, Eftekhari S, Chizari M, Sabernavaei M, Jafari D, Mirzabeigi P. A review of potential suggested drugs for coronavirus disease (COVID-19) treatment. Eur J Pharmacol2021;895:173890. doi: 10.1016/j.ejphar.2021.173890 pmid: 33482181

9 Larder BA, Darby G, Richman DD. HIV with reduced sensitivity to zidovudine (AZT) isolated during prolonged therapy. Science 1989;243:1731-4. doi: 10.1126/science.2467383 pmid: 2467383

10 Waters L. BHIVA guidelines for the treatment of HIV-1-positive adults with antiretroviral therapy 2015 (2016 interim update). BHIVA, 2016.

11 Renaud C, Kuypers J, Englund JA. Emerging oseltamivir resistance in seasonal and pandemic influenza A/H1N1. J Clin Virol 2011;52:70-8. doi: 10.1016/j.jcv.2011.05.019 pmid: 21684202

12 Gunst JD, Staerke NB, Pahus MH, etal. Efficacy of the TMPRSS2 inhibitor camostat mesilate in patients hospitalized with Covid-19-a double-blind randomized controlled trial. EClinicalMedicine 2021:100849. doi: 10.1016/j.eclinm.2021.100849 pmid: 33903855

13 Kang YL, Chou YY, Rothlauf PW, etal. Inhibition of PIKfyve kinase prevents infection by Zaire ebolavirus and SARS-CoV-2. Proc Natl Acad Sci U S A 2020;117:20803-13. doi: 10.1073/pnas.2007837117 pmid: 32764148

14 Riva L, Yuan S, Yin X, etal. Discovery of SARS-CoV-2 antiviral drugs through large-scale compound repurposing. Nature 2020;586:113-9. doi: 10.1038/s41586-020-2577-1 pmid: 32707573

15 Jiang Y, Yin W, Xu HE. RNA-dependent RNA polymerase: structure, mechanism, and drug discovery for covid-19. Biochem Biophys Res Commun 2021;538:47-53. doi: 10.1016/j.bbrc.2020.08.116 pmid: 32943188

16 Pilkington V, Pepperrell T, Hill A. A review of the safety of favipiravir-a potential treatment in the COVID-19 pandemic? J Virus Erad 2020;6:45-51. doi: 10.1016/S2055-6640(20)30016-9 pmid: 32405421

17 Painter WP, Holman W, Bush JA, etal. Human safety, tolerability, and pharmacokinetics of molnupiravir, a novel broad-spectrum oral antiviral agent with activity against SARS-CoV-2. Antimicrob Agents Chemother 2021;65:AAC.02428-20. doi: 10.1128/AAC.02428-20. pmid: 33649113

18 Lokhande AS, Devarajan PV. A review on possible mechanistic insights of nitazoxanide for repurposing in COVID-19. Eur J Pharmacol 2021;891:173748. doi: 10.1016/j.ejphar.2020.173748 pmid: 33227285

19 Morokutti-Kurz M, Fröba M, Graf P, etal. lota-carrageenan neutralizes SARS-CoV-2 and inhibits viral replication in vitro. PLoS One 2021;16:e0237480. doi: 10.1371/journal.pone.0237480. pmid: 33596218

20 Godlee F. Covid-19: the lost lessons of Tamiflu. BMJ2020;371:m4701. doi: 10.1136/bmj.m4701

This article is made freely available for use in accordance with BMJ's website terms and conditions for the duration of the covid-19 pandemic or until otherwise determined by BMJ. You may use, download and print the article for any lawful, non-commercial purpose (including text and data mining) provided that all copyright notices and trade marks are retained. 